\title{
The burden of nausea and vomiting during pregnancy: severe impacts on quality of life, daily life functioning and willingness to become pregnant again - results from a cross-sectional study
}

\author{
Kristine Heitmann ${ }^{1,3}$, Hedvig Nordeng ${ }^{1}$, Gro C. Havnen², Anja Solheimsnes ${ }^{3}$ and Lone Holst ${ }^{3 *}$ (D)
}

\begin{abstract}
Background: Though nausea and vomiting is very common during pregnancy, no studies have investigated the impact of this condition on the women's daily lives in a Scandinavian population. The aim of this study was to describe the burden of nausea and vomiting during pregnancy (NVP) on global quality of life, daily life functioning and willingness to become pregnant again according to the severity of NVP symptoms.

Methods: This study is a cross-sectional population-based study conducted in Norway. Pregnant women and mothers with children $<1$ year of age with current or prior NVP were eligible to participate. Data were collected through an anonymous on-line questionnaire accessible from November $10^{\text {th }}, 2014$ to January $31^{\text {st }}$, 2015. Severity of NVP was measured using the 24-h Pregnancy Unique Quantification of Emesis Scale (PUQE). Associations between severity of NVP, daily life functioning and willingness to become pregnant again were tested using chisquare tests. Associations with global quality of life measured in terms of the Quality of Life Scale (QOLS) were estimated using generalized linear models and reported as unstandardized regression coefficients ( $\beta$ ) with 95\% confidence intervals (Cl).
\end{abstract}

Results: 712 women with NVP were included in the study. NVP was significantly associated with several characteristics, including daily life functioning, quality of life and willingness to become pregnant again. The negative impact was greater the more severe the symptoms were, although considerable adverse effects were also seen among women with mild and moderate NVP symptoms. Over one fourth of the women with severe NVP considered terminating the pregnancy due to NVP, and three in four considered not to get pregnant again. Severity of NVP remained significantly associated with reduced global quality of life when adjusting for maternal characteristics and illnesses with $\beta(95 \% \mathrm{Cl})=-10.9(-16.9,-4.9)$ for severe versus mild NVP.

Conclusions: NVP as measured by PUQE had a major impact on various aspects of the women's lives, including global quality of life and willingness to become pregnant again.

Keywords: Pregnancy, Morning sickness, Hyperemesis gravidarum, NVP, Burden of illness, Quality of life, Termination of pregnancy

\footnotetext{
* Correspondence: lone.holst@farm.uib.no

${ }^{3}$ Department of Global Public Health and Primary Care, University of Bergen,

P-Box 7804N-5020 Bergen, Norway

Full list of author information is available at the end of the article
} 


\section{Background}

Most pregnant women experience pregnancy-related conditions, of which nausea and vomiting during pregnancy (NVP) is by far one of the most common. Nausea affects approximately $70-80 \%$ of the pregnant population, and additional vomiting is experienced by about $50 \%$ [1-3]. The symptoms of NVP range from mild to severe, with hyperemesis gravidarum (HG) at the most severe end of the scale. HG is characterised by excessive nausea and vomiting, leading to dehydration, electrolyte and nutritional disturbances, which often necessitates hospitalisation $[4,5]$.

Given the high prevalence of NVP and its most often self-limiting nature, health care providers may tend to trivialise its impact [6]. Though NVP in general is not associated with increased risk of adverse pregnancy outcomes, NVP imposes significant negative impact on the women's lives [7]. An extensive review of the literature from 1999 to 2011 included 38 studies that investigated the impact of NVP on health related quality of life and occupational, social and daily life functioning [7]. The review concluded that NVP causes decreased quality of life, and has adverse effects on social, occupational, and domestic life functioning [7]. Findings indicate that the effects of NVP are amplified with increased severity of NVP symptoms. Furthermore, an increased risk of comorbidity, especially with feelings of depression and heartburn and reflux problems has been described in the literature [8] posing an even larger burden on the women.

None of the studies included in the literature review were conducted in Norway or any other Scandinavian country. Cultural differences and differences between countries with respect to health care systems could infer that results obtained in other countries may not apply for the Norwegian pregnant population. In Norway there are approximately 60.000 births annually. The pregnancy care programme is free of charge. Furthermore Norwegian employees are entitled to sickness benefit if occupationally disabled due to own illness. The sick leave might be full time or graded (part time).

Previous studies have evaluated health related quality of life among women with NVP with generic health status measures such as the Medical Outcomes Study Short Form (SF36), SF12 (abbreviated version of SF36), and the NVP specific NVPQOL developed by Magee et al. [9-11]. Studies demonstrate great impact of NVP on health related quality of life, with increased adverse effects according to increased severity of NVP [9, 10, 12, 13]. Effects have been found on physical, social and emotional functioning, bodily pain, general health perceptions, vitality and mental health. However, health related quality of life instruments are focused on health status and do not capture how satisfied the women are with broader life domains. In specific, independence and material wellbeing are not captured in health status instruments $[14,15]$. The Quality of Life Scale (QOLS) belongs to the global or overall quality of life tools, and is a questionnaire measuring an individual's overall satisfaction with life using 16 questions covering relationships and material well-being, health and functioning, and personal, social and community commitment [15-18].

To the best of our knowledge, no studies have been performed with this perspective in women with NVP. Utilisation of the QOLS among women with NVP could be of great value in terms of obtaining a broader understanding of quality of life in this group. Such understanding is valuable in order to optimize pregnancy care for this patient group.

The primary aim of this study was to describe the impact of NVP on global quality of life as measured by QOLS, according to the severity of NVP symptoms as determined by PUQE. Secondary aims were to describe the impact of NVP on daily life functioning and willingness to become pregnant again according to the severity of NVP symptoms.

\section{Methods}

This study is a cross-sectional, population-based study [19]. Pregnant women and new mothers (women with a child of $<1$ year of age), who had experienced NVP during their current or last pregnancy, were invited to complete an anonymous on-line questionnaire (Additional file 1). The questionnaire was administered by SurveyXact and was accessible from $10^{\text {th }}$ November 2014 to $31^{\text {st }}$ January 2015. The questionnaire was accessible via banners with invitations to participate in the study. Banners were posted on national websites and social networks commonly visited by the pregnant population and/or new mothers ("altformamma.no", "mamma.no", "tryggmammamedisin.no", "foreldre.no's" Facebook page). The link was also posted on a Facebook page specifically created for this project, enabling the link to be shared on social media.

\section{Measures}

The questionnaire included questions on maternal characteristics, peak severity of NVP and comorbidity. The impact of NVP was measured by a range of questions about domestic, social and occupational life functioning. The questionnaire also explored questions related to the willingness to get pregnant again. The questionnaire was reviewed by representatives from the Norwegian patient organisation for hyperemesis, Hyperemesis Norge. 


\section{Classification of NVP, severity of symptoms}

NVP was measured and classified into three groups of different severity by using the 24-h Pregnancy Unique Quantification of Emesis Scale (PUQE) [20]. PUQE consists of three items that are used to assess the severity of NVP; the number of hours of nausea, number of episodes of retching and number of episodes of vomiting within the last $24 \mathrm{~h}$. Each item has five options which are scored from 1 to 5 points. The PUQE-score is calculated by adding the values from each item which adds up to a total score that ranges from 3 to 15 points. The obtained total PUQE-score was used to classify the severity of NVP into: mild $\leq 6$ points; moderate 7-12 points; severe $\geq 13$ points. PUQE has been validated and a significant association between PUQE and risk of hospitalisation due to severe NVP, increased healthcare costs because of NVP, reduced well-being/QOL, and inability to take iron supplements is described [21, 22]. A Norwegian translated version of PUQE that was recently validated was used in this current study [22] and is currently recommended used in routine antenatal care in Norway [23]. The version was adapted so that the women not being at the peak of their symptoms were asked to recall the extent of their NVP for a typical $24 \mathrm{~h}$ in the period with the most severe symptoms.

\section{Impact on domestic, social and occupational functioning and family planning}

The women were asked about how their NVP symptoms affected their daily life. A list of potential areas NVP could impact was developed based on previous findings in the literature, and resulted in the first five items included in Table 5. The women were posed five questions about NVP's negative impact on ability to perform domestic chores, social life, relationship with partner, ability to care for children and work capacity (as shown in Table 5), to which the women could respond "none", "minor", "major", or "not relevant". The women were also asked if they had been on sick leave due to NVP (yes/no/not relevant). In addition, the women were asked about if they ever considered terminating their pregnancy due to their NVP symptoms and if they considered not getting pregnant again due to NVP, both to which the women could respond in free text entry fields. The responses were categorised into yes, no or unsure.

\section{Measures of global quality of life}

Global quality of life was measured by using the Quality of Life Scale (QOLS) instrument [18]. Originally, it was developed by Flanagan to measure quality of life among the general population [16-18]. The QOLS explores factors such as material comforts, health, relationships with family members and others, participation in organisations, public affairs and volunteering, socialising, work and personal development [18]. The scale was later modified by Burckhardt et al. for patients and a $16^{\text {th }}$ item was added - independence, ability to do for oneself $[18,24]$. The women were asked to rate their current level of satisfaction with the item in question by ticking off on a seven point Likert scale ranging from very satisfied to very dissatisfied. The total QOLS score is calculated by adding up the items, and ranges from a minimum of 16 to a maximum of 112 where higher scores indicate better global quality of life.

The 16-item adapted version has been applied and validated in numerous studies across patient groups and cultures to gather quantitative information on quality of life $[15,18]$. Average total score for healthy populations is approximately 90 [18]. For women in Norway the reference value for the global quality of life is a QOLS score of 85 (SD 12.3) [14]. The mean total QOLS score among women who reported having diseases or health problems in the Norwegian study was 81.0 (SD 12.8) [14]. For patients with fibromyalgia, the score ranged from approximately 70 to $73[18,25,26]$.

A validated translated Norwegian version was applied in this current study [27]. In the validation study of the Norwegian version of the QOLS, internal consistency (Cronbach's alpha) was 0.86 and 0.89 at time 1 and 2, respectively, with a test-retest reliability of 0.83 [27].

\section{Potentially confounding factors}

The women were asked about several socio-demographic factors and health conditions that previously have been associated with NVP. The socio-demographic variables included parity; maternal age; pre-pregnancy body mass index (BMI); smoking during pregnancy; use of folic acid; marital status; education; and working status. The variables are categorised as presented in Table 1.

Maternal health variables included short term illnesses and chronic diseases. A list of nine short term illnesses was presented to the women who could specify which of the illnesses they had experienced during pregnancy. These were heartburn and reflux problems, headache, constipation, common cold, pain in back, neck and/or pelvis, sleeping problems, urinary tract infection, other infections, and "other" (that could be specified in a free text entry field). The number of short term illnesses was summed up and categorised into $\leq 2,3-4$ and $\geq 5$.

The women were also asked to report if they suffered from any chronic disease such as allergy, asthma, diabetes (type 1 or 2), epilepsy, cardiovascular diseases, muscle or skeletal problems, hyper-/hypothyroidism, 
Table 1 Maternal characteristics according to severity of NVP as defined by PUQE

\begin{tabular}{|c|c|c|c|c|c|}
\hline & \multicolumn{5}{|l|}{$\mathrm{PUQE}^{\mathrm{a}}$} \\
\hline & \multirow{2}{*}{$\begin{array}{l}\text { Total } \\
N=712 \text { n (\%) }\end{array}$} & \multirow{2}{*}{$\begin{array}{l}\text { Mild } \\
N=62 \mathrm{n}(\%)\end{array}$} & \multirow{2}{*}{$\begin{array}{l}\text { Moderate } \\
N=439 \text { n (\%) }\end{array}$} & \multirow{2}{*}{$\begin{array}{l}\text { Severe } \\
N=210 \mathrm{n}(\%)\end{array}$} & \multirow[t]{2}{*}{$\overline{p \text {-value }}{ }^{\mathrm{b}}$} \\
\hline & & & & & \\
\hline \multicolumn{6}{|l|}{ Parity } \\
\hline 0 previous live births & $382(53.7)$ & $38(61.3)$ & $241(54.9)$ & $103(49.0)$ & \multirow[t]{2}{*}{0.185} \\
\hline$\geq 1$ previous live births & $327(45.9)$ & $24(38.7)$ & $197(44.9)$ & $106(50.5)$ & \\
\hline \multicolumn{6}{|l|}{ Age, years } \\
\hline Under 25 & $145(20.4)$ & $11(17.7)$ & $87(19.8)$ & $46(21.9)$ & \multirow[t]{4}{*}{0.443} \\
\hline $25-29$ & $273(38.3)$ & $27(43.5)$ & 157 (35.8) & $89(42.4)$ & \\
\hline $30-39$ & $281(39.5)$ & $23(37.1)$ & $187(42.6)$ & $71(33.8)$ & \\
\hline Over 40 & $13(1.8)$ & $1(1.6)$ & $8(1.8)$ & $4(1.9)$ & \\
\hline \multicolumn{6}{|l|}{ Body Mass Index $(\mathrm{BMI})^{c}$} \\
\hline Underweight & $33(4.6)$ & $2(3.2)$ & $23(5.2)$ & $8(3.8)$ & \multirow[t]{4}{*}{0.615} \\
\hline Normal weight & $421(59.1)$ & $44(71.0)$ & $253(57.6)$ & $124(59.0)$ & \\
\hline Overweight & $139(19.5)$ & $10(16.1)$ & 86 (19.6) & $42(20.0)$ & \\
\hline Obese & $118(16.6)$ & $6(9.7)$ & $76(17.3)$ & $36(17.1)$ & \\
\hline \multicolumn{6}{|l|}{ Smoking } \\
\hline No & $684(96.1)$ & $61(98.4)$ & $422(96.1)$ & $200(95.2)$ & \multirow[t]{2}{*}{0.557} \\
\hline Yes & $27(3.8)$ & $1(1.6)$ & $16(3.6)$ & $10(4.8)$ & \\
\hline \multicolumn{6}{|l|}{ Use of folic acid } \\
\hline Before and/or during pregnancy & $673(94.8)$ & $57(91.9)$ & $419(95.7)$ & $197(93.8)$ & \multirow[t]{2}{*}{0.270} \\
\hline No & $37(5.2)$ & $5(8.1)$ & $19(4.3)$ & $13(6.2)$ & \\
\hline \multicolumn{6}{|l|}{ Marital status } \\
\hline Married/cohabitating & $661(92.8)$ & $55(88.7)$ & $408(92.9)$ & $197(93.8)$ & \multirow[t]{2}{*}{0.363} \\
\hline Not married/cohabiting & $51(7.2)$ & $7(11.3)$ & $31(7.1)$ & $13(6.2)$ & \\
\hline \multicolumn{6}{|l|}{ Education $^{d}$} \\
\hline Primary or secondary & $219(30.8)$ & $16(25.8)$ & $127(28.9)$ & $76(36.2)$ & \multirow[t]{4}{*}{0.230} \\
\hline Bachelor degree & $292(41.0)$ & $25(40.3)$ & $183(41.7)$ & $84(40.0)$ & \\
\hline Master degree & $170(23.9)$ & $20(32.3)$ & $110(25.1)$ & $40(19.0)$ & \\
\hline Other & $30(4.2)$ & $1(1.6)$ & $19(4.3)$ & $10(4.8)$ & \\
\hline \multicolumn{6}{|l|}{ Work situation } \\
\hline Student & $57(8.0)$ & $6(9.7)$ & $35(8.0)$ & $16(7.6)$ & \multirow[t]{4}{*}{0.458} \\
\hline Employed & $570(80.1)$ & $51(82.3)$ & $351(80.0)$ & $168(80.0)$ & \\
\hline Unemployed & $53(7.4)$ & $1(1.6)$ & $32(7.3)$ & $19(9.0)$ & \\
\hline Other & $32(4.5)$ & $4(6.5)$ & $21(4.8)$ & $7(3.3)$ & \\
\hline
\end{tabular}

Abbreviations: PUQE, $24 \mathrm{~h}$ Pregnancy Unique Quantification of Emesis; NVP, nausea and vomiting of pregnancy; OR, odds ratio; $\mathrm{Cl}$, confidence interval Numbers do not always add up due to missing numbers

${ }^{a}$ As classified by PUQE: mild: $\leq 6$ points; moderate: $7-12$ points; severe $\geq 13$

${ }^{b}$ Chi-square test or Fisher's exact test when expected count was less than 5 . Adjusted for all other variables in the table

'Body mass index (BMI) is the weight in kilograms divided by the square of the height in metres

underweight: $<18.5 \mathrm{~kg} / \mathrm{m}^{2}$, normal weight: $18.5-24.9 \mathrm{~kg} / \mathrm{m}^{2}$; overweight: $25.0-29.9 \mathrm{~kg} / \mathrm{m}^{2}$, obese $\geq 30 \mathrm{~kg} / \mathrm{m}^{2}$. Pre-pregnancy BMl is given

${ }^{d}$ Primary: $\leq 10$ years of education (the Norwegian compulsory primary + secondary school)

secondary: 11-13 years (high school/upper secondary or vocational school)

depression/anxiety, migraine and "other". For each chronic disease they were presented, the women could tick a box for affirmative response. The option "other" could be specified in a free text entry field. In addition the women were posed a question whether they had ever experienced any feelings of depression due to NVP while pregnant with the possibility to tick off for never, seldom, sometimes, most of the time or always. 


\section{Statistical analyses}

Descriptive statistics were utilised as appropriate. The Pearson chi-square or Fisher's exact tests were used to assess the relationship between the severity of NVP (classified as mild, moderate and severe as defined by PUQE) on domestic, social and occupational functioning and family planning as well as socio-demographic and maternal health characteristics.

Unadjusted generalized linear models (GLM) with identity link function and normal distribution were used to analyse associations between severity of NVP (PUQE-categories) and quality of life (QOLS scores) both in the total population and in subgroups stratified according to the woman's status at time of participation (currently pregnant, currently pregnant and experiencing NVP, new mother) to assess effect modification by sub-groups.

Since the women were asked about current quality of life and it is unlikely that NVP could affect quality of life also after birth, women who were no longer pregnant at the time of report were excluded in further analyses regarding the association between NVP and QOLS to reveal the effect of potential confounders. Firstly, unadjusted GLM models for each potential confounder were estimated. Secondly, the association between NVP and QOLS were estimated using GLM with two different levels of adjustment, and the following variables were adjusted for in each model:

Model 1: Adjustment for socio-demographic characteristics: Age, education, parity, occupational status, marital status, smoking during pregnancy, use of folic acid during pregnancy and body mass index.

Model 2: Adjustment for the same variables as in Model 1 plus additional adjustment for short term illnesses $(\leq 2 / 3-4 / \geq 5)$ and chronic disease (yes/no).

The potential confounders were chosen based on previously reported associations with NVP or QOLS in the literature and observed associations in the current study population. Health related variables were added as a separate step in Model 2 to observe how the association between NVP and QOLS changed after additional adjustment for co-morbidity.

The variables describing maternal characteristics were entered as categorical variables classified as shown in Table 1, with the exception of age which was entered as a continuous variable.

The residuals were assessed for normality with satisfying result for each analysis performed, and adjusted $R$ square was reported for each model.

To further explore the relationship between severity of NVP and quality of life kernel density curves for the distribution of QOLS were fitted separately for each category of NVP including only women who were pregnant at time of participation.
All statistical analyses were performed using Statistical Package for the Social Sciences (SPSS) version 20.0 (IBM SPSS Statistics 20) for Windows (SPSS, Chicago, IL, USA).

\section{Results}

Overall, 712 women with NVP completed the questionnaire and were included in the study.

The study participants were comparable to the general Norwegian birthing population with respect to geographic region of residence, maternal age, marital status and smoking status. A larger proportion of the study participants, however, had a higher education (B.Sc. or higher) than the women in the general birthing population, $65 \%$ vs. $47 \%$, respectively [19].

In total, 447 (62.8\%) of the 712 women were pregnant at time of participation and $265(37.2 \%)$ were a new mother with a child $<1$ year of age. As defined by PUQE, 62 (8.7\%), 439 (61.7\%) and 210 (29.5\%) had mild, moderate and severe NVP, respectively (Table 1$)$. There was no association between socio-demographic factors and NVP (Table 1) or having a chronic disease and NVP (Table 2). Severity of NVP however, was significantly associated with heartburn and reflux problems $(71.9 \%$ among women with severe NVP vs. $58.1 \%$ among women with mild NVP) and headache $(63.8 \%$ among women with severe NVP vs. $46.8 \%$ among women with mind NVP) (Table 2). Moreover, the more severe NVP symptoms, the more often the women had feelings of depression; 39.0\% feeling depressed "most of the time" among women with severe NVP vs. $4.8 \%$ among women with mild NVP.

In the total study population, a mean QOLS-score of 76.3 (95\% CI 74.5-78.0) was found. Mean score was found to be 80.5 (95\% CI 78.5-82.5) among the new mothers, 72.0 (95\% CI 70.4-73.7) among women who were pregnant at time of participation and 68.1 (95\% CI 66.0-70.2) among women who experienced NVP at time of participation (Table 3). Figure 1 shows the kernel density curves for the distribution of QOLS-scores according to the three groups of NVP severity among women that were currently pregnant. The distributions among women with severe and moderate NVP were shifted downwards compared to women with mild NVP.

Severity of NVP symptoms was significantly associated with global quality of life among pregnant women and women experiencing NVP at time of participation, but not among the new mothers (Table 3). Lowest QOLSscore was reported by women who were pregnant and experienced severe NVP at the time of completing the questionnaire (63.6, 95\% CI 56.2-71.0) (Table 3).

In adjusted analyses including only pregnant women (Table 4), increased NVP severity was significantly 
Table 2 Comorbidity according to NVP severity

\begin{tabular}{|c|c|c|c|c|c|}
\hline & \multicolumn{5}{|l|}{ PUQE } \\
\hline & \multirow{2}{*}{$\begin{array}{l}\text { Total } \\
N=712 \mathrm{n}(\%)\end{array}$} & \multirow{2}{*}{$\begin{array}{l}\text { Mild } \\
N=62 \mathrm{n}(\%)\end{array}$} & \multirow{2}{*}{$\begin{array}{l}\text { Moderate } \\
N=439 \text { n (\%) }\end{array}$} & \multirow{2}{*}{$\begin{array}{l}\text { Severe } \\
N=210 \mathrm{n}(\%)\end{array}$} & \multirow[b]{2}{*}{$p$-value ${ }^{a}$} \\
\hline & & & & & \\
\hline Heartburn and reflux problems & $458(64.3)$ & $36(58.1)$ & $270(61.5)$ & $151(71.9)$ & 0.02 \\
\hline Headache & $441(61.9)$ & $29(46.8)$ & $277(63.1)$ & $134(63.8)$ & 0.04 \\
\hline Constipation & $431(60.5)$ & $45(72.6)$ & $267(60.8)$ & $118(56.2)$ & 0.07 \\
\hline Common cold & $274(38.4)$ & $25(40.3)$ & $175(39.9)$ & $73(34.8)$ & 0.43 \\
\hline Pain in back, neck or pelvic & $469(65.8)$ & $41(66.1)$ & $297(67.7)$ & $130(61.9)$ & 0.35 \\
\hline Sleep problems & $450(63.2)$ & $33(53.2)$ & $282(64.2)$ & $134(63.8)$ & 0.24 \\
\hline Urinary tract infection & $114(15.9)$ & $7(11.3)$ & $67(15.3)$ & 39 (18.6) & 0.33 \\
\hline Other & $91(12.8)$ & $9(14.5)$ & $60(13.7)$ & $22(10.5)$ & 0.48 \\
\hline Any chronic illness & $345(48.5)$ & $21(33.9)$ & $221(50.3)$ & $103(49.0)$ & 0.051 \\
\hline \multicolumn{6}{|l|}{ Feelings of depression due to NVP } \\
\hline Never & $61(8.6)$ & $18(29.0)$ & $37(8.4)$ & $6(2.9)$ & \multirow[t]{5}{*}{$<0.001$} \\
\hline Seldom & $121(17.0)$ & $22(35.5)$ & $82(18.7)$ & $17(8.1)$ & \\
\hline Sometimes & $323(45.4)$ & 19 (30.6) & $211(48.1)$ & $93(44.3)$ & \\
\hline Most of the time & $187(26.3)$ & $3(4.8)$ & $101(23.0)$ & $82(39.0)$ & \\
\hline Always & $20(2.8)$ & $0(0.0)$ & $8(1.8)$ & $12(5.7)$ & \\
\hline
\end{tabular}

${ }^{a}$ Chi-square test or Fisher's exact test when expected count was less than 5 . Bold $p$-values indicate statistically significant differences between the groups

associated with reduced QOLS score after adjustment for maternal characteristics in Model 1 with $\beta(95 \% \mathrm{CI})=$ $-11.7(-17.6,-5.7)$ for severe NVP compared with mild NVP. The association was slightly reduced after adjustment for short term illnesses and chronic disease in Model 2, but was still significant with $\beta(95 \% \mathrm{CI})=-10.9$ $(-16.9,-4.9)$.
NVP greatly interfered with the women's daily lives and was found to have important adverse effects on daily life functioning (Table 5). More than $70 \%$ of the women in the total study population experienced that NVP had a major adverse impact on taking care of household chores and on social life functioning. As many as $63.5 \%$ reported that NVP had a major adverse effect on the

Table 3 Global quality of life (QOLS) according to severity of NVP among the total population and selected sub-populations of study participants

\begin{tabular}{|c|c|c|c|c|c|}
\hline \multirow[t]{3}{*}{ QOLS } & \multicolumn{5}{|l|}{ PUQE } \\
\hline & \multirow{2}{*}{$\begin{array}{l}\text { Total } \\
\text { Mean of total } \\
\text { score }(95 \% \mathrm{Cl})\end{array}$} & \multirow{2}{*}{$\begin{array}{l}\text { Mild } \\
\text { Mean of total } \\
\text { score }(95 \% \mathrm{Cl})\end{array}$} & \multirow{2}{*}{$\begin{array}{l}\text { Moderate } \\
\text { Mean of total } \\
\text { score }(95 \% \mathrm{Cl})\end{array}$} & \multirow{2}{*}{$\begin{array}{l}\text { Severe } \\
\text { Mean of total } \\
\text { score }(95 \% \mathrm{Cl})\end{array}$} & \multirow[t]{2}{*}{$p$-value } \\
\hline & & & & & \\
\hline \multicolumn{6}{|c|}{$\begin{array}{l}\text { Total study population } \\
(n=712)\end{array}$} \\
\hline QOLS score & $76.3(74.5-78.0)$ & $80.1(75.7-84.4)$ & $75.3(73.7-77.0)$ & 73.4 (71.0-75.8) & 0.03 \\
\hline \multicolumn{6}{|c|}{$\begin{array}{l}\text { Pregnant at time of } \\
\text { participation }(n=447)\end{array}$} \\
\hline QOLS score & $72.0(70.4-73.7)$ & 80.3 (74.9-85.8) & $72.5(70.6-74.4)$ & $67.2(63.7-70.8)$ & $<0.001$ \\
\hline \multicolumn{6}{|c|}{$\begin{array}{l}\text { Pregnant and } \\
\text { experiencing NVP } \\
\text { at time of } \\
\text { participation }(n=286)\end{array}$} \\
\hline QOLS score & $68.1(66.0-70.2)$ & 73.3 (68.9-77.6) & $67.0(64.4-69.5)$ & $63.6(56.2-71.0)$ & $<0.001$ \\
\hline \multicolumn{6}{|c|}{$\begin{array}{l}\text { New mother at time } \\
\text { of participation }(n=264)\end{array}$} \\
\hline QOLS score & $80.5(78.5-82.5)$ & 79.4 (72.2-86.6) & 81.3 (78.8-83.8) & 79.6 (75.9-83.2) & 0.69 \\
\hline
\end{tabular}

Abbreviations: QOLS, Quality of life scale; Cl, confidence interval; PUQE, $24 \mathrm{~h}$ Pregnancy-Unique Quantification of Emesis. QOLS score among women in the general Norwegian population was 85 [14]

${ }^{a}$ ANOVA. Bold $p$-values indicate statistically significant differences between the groups 


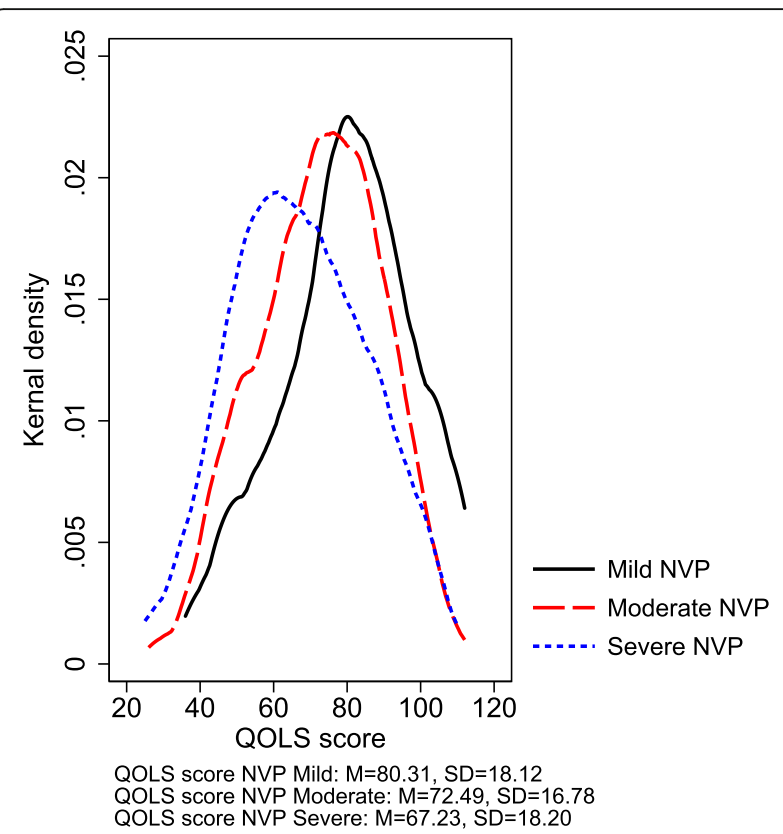

Fig. 1 QOLS score according to NVP severity as defined by PUQE. The figure is based on analyses including only women pregnant at time of participation. QOLS score among women in the general Norwegian population was 85 [14]

ability of care for their children, and for approximately $80 \%$ the relationship with partner was negatively affected to some extent. Work capacity was impaired due to NVP for most of the women, and 428 (60.1\%) had been on sick leave due to NVP. Family planning was also affected, especially among women with severe symptoms of which $75.7 \%$ of the women considered not to get pregnant again. A total of $26.7 \%$ of the women with severe symptoms considered to terminate the pregnancy due to NVP.

Severity of NVP was significantly associated with impaired ability to engage in domestic, occupational and social activities, with increased impact according to increased severity (Table 5). More women with severe symptoms reported major impact on the various parameters, however it is worth noticing that a large proportion of women with moderate symptoms reported major adverse impact on domestic, social and occupational functioning.

\section{Discussion}

Several of the findings are important for clinical practice. Global quality of life was significantly reduced according to severity of NVP. The study also shows that NVP has impact on daily life functioning and willingness to become pregnant again. This study is the first study to assess the impact of NVP on these outcomes in a Scandinavian population.

Previous studies have found major impacts of NVP on health related quality of life [7]. This current study also demonstrates that NVP has adverse effects on the global quality of life measured by the QOLS. The total QOLS score among women who were pregnant or who experienced NVP at time of participation were 72 and 68, respectively. This is low compared to other populations such as women in the general Norwegian population with an average score of 85 [14]; patients with various chronic diseases such as rheumatic disease groups, psoriasis and chronic obstructive pulmonary disease, who score above 80 on the QOLS [18]; fibromyalgia patients with scores around 70-73 [18, 25, 26]; and Israeli patients with posttraumatic stress disorder with a score of 61 [18]. Furthermore, we found that global quality of life was significantly associated with the severity of NVP. The mean total QOLS score among women with severe NVP symptoms that were pregnant or were experiencing NVP at time of participation was 67 and 64, respectively, demonstrating that severe NVP affects global quality of life to a great extent. However, when only the new mothers were included in the analyses, no association with severity of NVP was detected. Furthermore, the mean QOLS score among the new mothers was above 80 , and higher than for the two other sub-groups, approaching that of the general Norwegian population [14]. This is reassuring as it may imply that the severity of NVP experienced while pregnant does not affect quality of life after birth, and that global quality of life normalises after birth for most women, despite having suffered from severe NVP while pregnant.

We also investigated whether the inclusion of potential confounders had an impact on the association between NVP and QOLS for pregnant women. The adjusted analysis demonstrated that the association could not be explained by the investigated factors.

Major impact of NVP on the women's quality of life has also previously been demonstrated in studies from other countries. In line with our results, the effects have been found to be increased according to the severity of the NVP symptoms $[10,12,13]$. Women suffering from more severe symptoms were found to have a physical quality of life close to that among women with breast cancer, and a mental quality of life comparable to that seen among women with postpartum depression [10].

In addition, this study demonstrates that NVP affects the women's daily life functioning and willingness to become pregnant again. Especially for the women with severe symptoms the adverse effects of NVP were found to be substantial. The fact that more than one fourth of the women with severe symptoms reported that they had considered terminating the pregnancy, is highly concerning. Other studies conducted among women with HG report that 15\% of the women actually had terminated a pregnancy due to the severity of their symptoms [28]. A Canadian 
Table 4 Regression analyses for the association between severity of NVP and global quality of life controlling for demographic variables, and comorbidity. ( $N=447)$

\begin{tabular}{|c|c|c|c|c|c|c|}
\hline & \multicolumn{2}{|l|}{ Univariate models } & \multicolumn{2}{|l|}{ Model 1} & \multicolumn{2}{|l|}{ Model 2} \\
\hline & $\begin{array}{l}\text { Unstandardized regression } \\
\text { coefficients }(\beta)(95 \% \mathrm{Cl})\end{array}$ & $p$-value & $\begin{array}{l}\text { Unstandardized regression } \\
\text { coefficients }(\beta)(95 \% \mathrm{Cl})\end{array}$ & $p$-value & $\begin{array}{l}\text { Unstandardized regression } \\
\text { coefficients }(\beta)(95 \% \mathrm{Cl})\end{array}$ & $p$-value \\
\hline \multicolumn{7}{|l|}{ Severity of NVP } \\
\hline Mild & Ref. & & Ref. & & Ref. & \\
\hline Moderate & $-7.8(-13.3,-2.4)$ & 0.005 & $-6.7(-12.0,-1.4)$ & 0.014 & $-5.9(-11.2,-0.5)$ & 0.032 \\
\hline Severe & $-13.1(-19.1,-7.0)$ & $<0.001$ & $-11.7(-17.6,-5.7)$ & $<0.001$ & $-10.9(-16.9,-4.9)$ & $<0.001$ \\
\hline \multicolumn{7}{|l|}{ Parity } \\
\hline 0 previous live births & Ref. & & Ref. & & Ref. & \\
\hline$\geq 1$ previous live births & $-4.7(-7.9,-1.4)$ & 0.005 & $-6.6(-10.0,-3.1)$ & $<0.001$ & $-6.7(-10.2,-3.2)$ & $<0.001$ \\
\hline Age, years & $0.3(-0.1,0.6)$ & 0.100 & $0.2(-0.2,0.6)$ & 0.299 & $0.2(-0.2,0.6)$ & 0.320 \\
\hline \multicolumn{7}{|l|}{ Body Mass Index (BMI) ${ }^{a}$} \\
\hline Underweight & -4.1 & 0.2 & $-2.4(-10.5,5.8)$ & 0.565 & $-1.7(-9.9,6.4)$ & 0.677 \\
\hline Normal weight & Ref. & & Ref. & & Ref. & \\
\hline Overweight & -2.7 & 0.1 & $-3.6(-7.8,0.5)$ & 0.087 & $-4.0(-8.2,0.1)$ & 0.056 \\
\hline Obese & -3.7 & 0.045 & $-5.6(-10.1,-1.1)$ & 0.014 & $-5.5(-9.9,-1.0)$ & 0.016 \\
\hline \multicolumn{7}{|l|}{ Smoking } \\
\hline No & Ref. & & Ref. & & Ref. & \\
\hline Yes & $2.2(-6.4,10.7)$ & 0.617 & $6.0(-2.5,14.4)$ & 0.166 & $5.9(-2.5,14.3)$ & 0.168 \\
\hline \multicolumn{7}{|l|}{ Use of folic acid } \\
\hline No & Ref. & & Ref. & & Ref. & \\
\hline Yes, before and/or during pregnancy & $1.8(-5.5,9.0)$ & 0.634 & $-1.4(-8.4,5.6)$ & 0.696 & $-1.1(-8.1,5.9)$ & 0.762 \\
\hline \multicolumn{7}{|l|}{ Marital status } \\
\hline Married/cohabitating & Ref. & & Ref. & & Ref. & \\
\hline Not married/cohabiting & $-6.0(-11.9,-0.1)$ & 0.046 & $-6.8(-12.6,-1.0)$ & 0.021 & $-6.9(-12.7,-1.1)$ & 0.019 \\
\hline \multicolumn{7}{|l|}{ Education ${ }^{b}$} \\
\hline Primary or secondary & $-8.5(-12.9,-4.1)$ & $<0.001$ & $-6.1(-11.0,-1.2)$ & 0.014 & $-6.1(-11.0,-1.2)$ & 0.015 \\
\hline Bachelor degree & $-6.4(-10.5,-2.3)$ & 0.002 & $-5.1(-9.2,-1.0)$ & 0.015 & $-5.0(-9.1,-0.8)$ & 0.018 \\
\hline Master degree & Ref. & & Ref. & & Ref. & \\
\hline Other & $-14.2(-22.3,-6.1)$ & 0.001 & $-13.0(-21.2,-4.8)$ & 0.002 & $-12.8(-21.0,-4.6)$ & 0.002 \\
\hline \multicolumn{7}{|l|}{ Work situation } \\
\hline Student & $-4.1(-10.3,2.1)$ & 0.198 & $-2.6(-8.8,3.6)$ & 0.407 & $-3.3(-9.5,2.9)$ & 0.290 \\
\hline Employed & Ref. & & Ref. & & Ref. & \\
\hline Unemployed & $-3.3(-10.2,3.6)$ & 0.344 & $3.3(-3.9,10.5)$ & 0.366 & $4.2(-3.0,11.4)$ & 0.256 \\
\hline Other & $0.9(-6.7,8.5)$ & 0.815 & $2.9(-4.4,10.3)$ & 0.436 & $4.4(-3.0,11.8)$ & 0.245 \\
\hline \multicolumn{7}{|l|}{ Number of short term illnesses } \\
\hline$\leq 2$ & Ref. & & - & - & Ref. & \\
\hline $3-4$ & $-4.2(-8.4,0.1)$ & 0.056 & & & $-3.2(-7.3,1.0)$ & 0.133 \\
\hline$\geq 5$ & $-6.2(-10.7,-1.8)$ & 0.007 & & & $-5.5(-9.9,-1.1)$ & 0.014 \\
\hline
\end{tabular}


Table 4 Regression analyses for the association between severity of NVP and global quality of life controlling for demographic variables, and comorbidity. ( $N=447)$ (Continued)

Chronic disease
No
Yes
Adjusted $R$ square
Abbreviations: Ref $=$ reference category. Models were estimated using generalized linear models with QOLS as dependent variable, identity link function and
assuming a normal distribution of QOLS. Only women who were currently pregnant are included in the analyses. Bold $p$-values indicate significant differences
between the groups
a Body mass index $(\mathrm{BMI})$ is the weight in kilograms divided by the square of the height in metres; underweight: $<18.5 \mathrm{~kg} / \mathrm{m}^{2}$, normal weight: $18.5-24.9 \mathrm{~kg} / \mathrm{m}^{2}$;
overweight: $25.0-29.9 \mathrm{~kg} / \mathrm{m}^{2}$, obese $\geq 30 \mathrm{~kg} / \mathrm{m}^{2}$
underweight:
bPrimary: $\leq 10$ years of education (the Norwegian compulsory primary + secondary school), secondary: $10-12$ years (high school/upper secondary or vocational school)

study also demonstrated that termination of pregnancy occurs due to NVP [29].

It is also worth noting that among women with severe symptoms, $76 \%$ reported that they considered never to get pregnant again, $84 \%$ reported that the NVP had major adverse effects on the ability to care for their children, and $43 \%$ reported major impact on the relationship with their partner, reflecting substantial effects on family life functioning. In total 94\% reported major impact on their work capacity and over $90 \%$ had been on sick leave due to NVP, illustrating that occupational functioning is affected for most women with severe NVP. However, considerable adverse effects were also seen among women with moderate symptoms, and even some women with mild symptoms reported major impact on different aspects of daily life functioning. This is in line with other studies describing that even mild NVP affected important part of the women's daily lives, such as caring for children, relationship with partner, work productivity and intent to become pregnant again [13, 30].

Our study implies that adequate management of NVP is not only important for moderate to severe cases, but also for mild cases. Health care providers should perform individual assessments of the degree of NVP and its implications on the woman's quality of life and daily life functioning for each woman presenting with NVP.

\section{Strengths and limitations}

This study has several strengths and limitations that need to be addressed. A conventional response rate could not be calculated due to the web-based design of the study. Furthermore, a self-selection bias of more motivated women cannot be ruled out, possibly explaining the relatively high proportion of women with severe NVP and thus leading to an over-estimation of the amount of women with severe symptoms. However, the utilisation of the internet for recruitment purposes and collection of data enabled a high number of women to be reached from all over Norway. The participants in this study were reasonably comparable to the general birthing population in Norway, with a strikingly similar geographic spread, with the exception of the somewhat higher rate of education among the participants [19]. This may be due to the high internet penetration in Norway. In total, $97 \%$ of the women aged 16-44 in Norway use internet on a daily basis [31], which may infer that this methodology is especially appropriate for the target population of this study. There is an increased use of the internet for research purposes [32]. Web-based recruitment has shown reasonable validity in epidemiological studies [33, 34]. Furthermore, the information reported in web-based questionnaires has similar quality to that reported in paper based questionnaires [35-37].

Our results rely on the women's accurate recall of the consequences experienced due to NVP. As most women were past the peak of NVP severity (94\%), maternal reporting of peak NVP severity was retrospective. This may have introduced a risk for overestimation of the NVP symptoms as shown by Koren et al. [38]. As women with severe symptoms might be overrepresented, this may have biased our results towards more severe consequences for the group as a whole. However, as we have information about the severity of the NVP symptoms, the results are presented according to the severity of NVP.

\section{Conclusion}

Global quality of life was significantly reduced according to severity of NVP. Severity of NVP was also significantly associated with negative effects on various aspects of daily life functioning and willingness to become pregnant again. Health care providers should be aware of the high burden NVP represents for the women, and provide the necessary support and care needed in each individual case. Prospective studies are needed to determine whether earlier treatment of women with NVP may reduce the need for sick leave, the risk of progression into severe symptoms and hospitalisation and reduce the adverse effects of NVP on the women's lives. 
Table 5 Negative impact of NVP on daily life functioning and willingness to get pregnant again

\begin{tabular}{|c|c|c|c|c|c|}
\hline & \multicolumn{5}{|l|}{ PUQE } \\
\hline & \multirow{2}{*}{$\begin{array}{l}\text { Total }^{\mathrm{b}} \\
N=712 \mathrm{n}(\%)\end{array}$} & \multirow{2}{*}{$\begin{array}{l}\text { Mild } \\
N=62 n(\%)\end{array}$} & \multirow{2}{*}{$\begin{array}{l}\text { Moderate } \\
N=439 \text { n (\%) }\end{array}$} & \multirow{2}{*}{$\begin{array}{l}\text { Severe } \\
N=210 \mathrm{n}(\%)\end{array}$} & \multirow[t]{2}{*}{$p$-value } \\
\hline & & & & & \\
\hline \multicolumn{6}{|c|}{$\begin{array}{l}\text { 1. Taking care of household } \\
\text { chores }\end{array}$} \\
\hline No impact & $29(4.1)$ & $14(22.6)$ & $14(3.2)$ & $1(0.5)$ & \multirow[t]{3}{*}{$<0.001$} \\
\hline Minor impact & $150(21.1)$ & $37(59.7)$ & $103(23.5)$ & $10(4.8)$ & \\
\hline Major impact & $533(74.9)$ & $11(17.7)$ & $322(73.3)$ & $199(94.8)$ & \\
\hline \multicolumn{6}{|l|}{ 2. Social life } \\
\hline No impact & $44(6.2)$ & $18(29.0)$ & $23(5.2)$ & $3(1.4)$ & \multirow[t]{3}{*}{$<0.001$} \\
\hline Minor impact & $155(21.8)$ & $34(54.8)$ & $103(23.5)$ & $17(8.1)$ & \\
\hline Major impact & $513(72.1)$ & $10(16.1)$ & $313(71.3)$ & $190(90.5)$ & \\
\hline \multicolumn{6}{|c|}{ 3. Relationship with partner $c, n=682$} \\
\hline No impact & $134(19.6)$ & $23(38.3)$ & $77(18.2)$ & $34(17.1)$ & \multirow[t]{3}{*}{$<0.001$} \\
\hline Minor impact & $306(44.9)$ & $32(53.3)$ & $193(45.7)$ & $80(40.2)$ & \\
\hline Major impact & $242(35.5)$ & $5(8.3)$ & $152(36.0)$ & $85(42.7)$ & \\
\hline \multicolumn{6}{|c|}{ 4. Ability to care for children ${ }^{d, n=351}$} \\
\hline No impact & $31(8.8)$ & $10(32.3)$ & $16(7.7)$ & $5(4.5)$ & \multirow[t]{3}{*}{$<0.001$} \\
\hline Minor impact & $97(27.6)$ & $17(54.8)$ & $67(32.2)$ & $13(11.6)$ & \\
\hline Major impact & $223(63.5)$ & $4(12.9)$ & $125(60.1)$ & $94(83.9)$ & \\
\hline \multicolumn{6}{|c|}{ 5. Work capacity e, $n=671$} \\
\hline No impact & $28(4.2)$ & $8(13.8)$ & $20(4.9)$ & $0(0.0)$ & \multirow[t]{3}{*}{$<0.001$} \\
\hline Minor impact & $147(21.9)$ & $40(69.0)$ & $95(23.2)$ & $12(5.9)$ & \\
\hline Major impact & 496 (73.9) & $10(17.2)$ & 294 (71.9) & $191(94.1)$ & \\
\hline \multicolumn{6}{|c|}{ 6. Sick leave due to NVP ${ }^{f, n=649}$} \\
\hline No & $221(34.1)$ & $50(84.7)$ & $153(38.8)$ & $18(9.2)$ & \multirow[t]{2}{*}{$<0.001$} \\
\hline Yes & $428(65.9)$ & $9(15.3)$ & $241(61.2)$ & $178(90.8)$ & \\
\hline \multicolumn{6}{|c|}{$\begin{array}{l}\text { 7. Considered to terminate } \\
\text { the pregnancy due to NVP }\end{array}$} \\
\hline No & $608(85.5)$ & $62(100.0)$ & $393(89.5)$ & $153(72.9)$ & \multirow[t]{3}{*}{$<0.001$} \\
\hline Yes & $100(14.1)$ & $0(0.0)$ & $44(10.0)$ & $56(26.7)$ & \\
\hline Unsure & $3(0.4)$ & $0(0.0)$ & $2(0.5)$ & $1(0.5)$ & \\
\hline \multicolumn{6}{|c|}{$\begin{array}{l}\text { 8. Consider not to get } \\
\text { pregnant again }\end{array}$} \\
\hline No & $333(46.8)$ & $54(87.1)$ & $233(53.1)$ & $46(21.9)$ & \multirow[t]{3}{*}{$<0.001$} \\
\hline Yes & $353(49.6)$ & $6(9.7)$ & $188(42.8)$ & $159(75.7)$ & \\
\hline Unsure & $25(3.5)$ & $2(3.2)$ & $18(4.1)$ & $5(2.4)$ & \\
\hline
\end{tabular}

Abbreviations: $\mathrm{Cl}$, confidence interval; PUQE, $24 \mathrm{~h}$ Pregnancy-Unique Quantification of Emesis; NVP, nausea and vomiting of pregnancy

${ }^{a}$ Chi-square test or Fisher's exact test when expected count were less than 5 . Bold $p$-values indicate statistically significant differences between the groups

${ }^{\text {b}}$ The sums do not always add up to total due to missing ("not relevant")

c3.8\% responded "not relevant"

$\mathrm{d}_{52.3 \%}$ did not have any children

e $6.8 \%$ responded "not relevant"

f $8.8 \%$ responded "not relevant" 


\section{Additional file}

Additional file 1: Questionnaire. (PDF $82 \mathrm{~kb}$ )

\begin{abstract}
Abbreviations
BMI: Body mass index; GLM: Generalised linear model; HG: Hyperemesis gravidarum; NVP: Nausea and vomiting during pregnancy; PUQE: $24 \mathrm{~h}$ Pregnancy-unique quantification of emesis-scale; QOLS: Quality of life scale; SPSS: Statistical Package for Social Sciences
\end{abstract}

\section{Acknowledgements}

We thank the providers of the websites for contributions in the recruitment phase, and all the women who participated in the study. We also thank the Statistics Service at the Department of Global Public Health and Primary Care for providing statistical advice and representatives from Hyperemesis Norge for reviewing the questionnaire. $\mathrm{KH}$ received funding for her $\mathrm{PhD}$ project from The Norwegian Research Council (Grant no. 195475).

\section{Funding}

Kristine Heitmann's Ph.D. was funded by the Norwegian Research Council (Norges Forskningsråd) Grant number 195475.

\section{Availability of data and material}

Data will not be shared as the participants were not informed about this possibility when they consented to participate in the study.

\section{Authors' contributions}

$\mathrm{KH}, \mathrm{LH}, \mathrm{GCH}$ and $\mathrm{HN}$ conceived and designed the study. AS collected the data. $\mathrm{KH}$ performed the statistical analyses in cooperation with the Statistics Service at the Department of Global Public Health and Primary Care and drafted the manuscript. All authors contributed to the interpretation of the results and to the final manuscript. All authors read and approved the final manuscript.

\section{Authors' information}

KH Ph.D., M.Sc.Pharm. is at the Department of Gobal Public Health and Primary Care, University of Bergen, Bergen, Norway.

HN Dr. Philos., M.Sc.Pharm. is a Professor and head of the Pharmacoepidemiology and Drug Safety Research Group at the School of Pharmacy, University of Oslo, Oslo, Norway, and a researcher at the Department of Child Health, Norwegian Institute of Public Health, Oslo, Norway. The focus of her research is medication use and safety during pregnancy and breastfeeding.

GCH M.Sc.Pharm. is a researcher who also works as a consultant at the Regional Medicines Information and Pharmacovigilance Centre (RELIS). She is experienced in counselling pregnant women about medicines.

AS M.Sc.Pharm is a newly graduated pharmacist who collected these data as part of her master thesis.

LH Ph.D., M.Sc.Pharm. is an Associate Professor in Social Pharmacy at the University of Bergen, Bergen, Norway. The focus of her research is herbal remedies and pregnant women.

\section{Competing interests}

The authors declare that they have no competing interests.

\section{Consent for publication}

Not applicable.

\section{Ethics approval and consent to participate}

The study was approved by the Regional Ethics Committee, Region West in Norway (Ref. 2014/1065). The Norwegian Social Science Data Services was also consulted.

Information about the study was presented to the respondents before they could enter the online questionnaire. This included the study objectives, the participants' right to withdraw at any time, and contact information to members of the research group. Next, the women had to answer the following question: "Are you willing to participate in the study?" If the woman ticked "yes", this was considered informed consent and she could continue with the survey.

\section{Author details}

${ }^{1}$ PharmacoEpidemiology and Drug Safety Research Group, School of Pharmacy, University of Oslo, Oslo, Norway. ${ }^{2}$ Regional Medicines Information and Pharmacovigilance Centre (RELIS), Oslo, Norway. ${ }^{3}$ Department of Global Public Health and Primary Care, University of Bergen, P-Box 7804N-5020 Bergen, Norway.

Received: 15 April 2016 Accepted: 8 February 2017

Published online: 28 February 2017

\section{References}

1. Einarson TR, Piwko C, Koren G. Quantifying the global rates of nausea and vomiting of pregnancy: a meta analysis. J Popul Ther Clin Pharmacol. 2013; 20(2):e171-83

2. Gadsby R, Barnie-Adshead AM, Jagger C. A prospective study of nausea and vomiting during pregnancy. Br J Gen Pract. 1993;43(371):245-8.

3. Klebanoff MA, Koslowe PA, Kaslow R, Rhoads GG. Epidemiology of vomiting in early pregnancy. Obstet Gynecol. 1985;66(5):612-6.

4. Gazmararian JA, Petersen R, Jamieson DJ, Schild L, Adams MM, Deshpande $A D$, et al. Hospitalizations during pregnancy among managed care enrollees. Obstet Gynecol. 2002;100(1):94-100.

5. Lee NM, Saha S. Nausea and vomiting of pregnancy. Gastroenterol Clin N Am. 2011:40(2):309-34

6. Heitmann $\mathrm{K}$, Svendsen HC, Sporsheim $\mathrm{IH}$, Holst L. Nausea in pregnancy: attitudes among pregnant women and general practitioners on treatment and pregnancy care. Scand J Prim Health Care. 2016:34(1):13-20.

7. Wood H, McKellar LV, Lightbody M. Nausea and vomiting in pregnancy: blooming or bloomin' awful? a review of the literature. Women Birth. 2013; 26(2):100-4

8. Heitmann $\mathrm{K}$, Holst L, Lupattelli A, Maltepe C, Nordeng $\mathrm{H}$. Treatment of nausea in pregnancy: a cross-sectional multinational web-based study of pregnant women and new mothers. BMC Pregnancy Childbirth. 2015;15(1):321.

9. Smith C, Crowther C, Beilby J, Dandeaux J. The impact of nausea and vomiting on women: a burden of early pregnancy. Aust N Z J Obstet Gynaecol. 2000;40(4):397-401.

10. Lacasse A, Rey E, Ferreira E, Morin C, Berard A. Nausea and vomiting of pregnancy: what about quality of life? BJOG. 2008;115(12):1484-93.

11. Magee LA, Chandra K, Mazzotta P, Stewart D, Koren G, Guyatt GH. Development of a health-related quality of life instrument for nausea and vomiting of pregnancy. Am J Obstet Gynecol. 2002;186(5 Suppl Understanding):S232-8.

12. Attard CL, Kohli MA, Coleman S, Bradley C, Hux M, Atanackovic G, et al. The burden of illness of severe nausea and vomiting of pregnancy in the united states. Am J Obstet Gynecol. 2002;186(5 Suppl Understanding):S220-7.

13. Clark S, Hughes B, McDonald SS. The impact of nausea and vomiting of pregnancy on quality of life: Report of a national consumer survey and recommendations for improving care. Obstet Gynecol Surv. 2013; 68(9 SUPPL. 1): S1-S10.

14. Wahl AK, Rustøen T, Hanestad BR, Lerdal A, Moum T. Quality of life in the general Norwegian population, measured by the quality of life scale (QOLSN). Qual Life Res. 2004;13(5):1001-9.

15. Burckhardt CS, Anderson KL, Archenholtz B, Hagg O. The Flanagan quality of life scale: evidence of construct validity. Health Qual Life Outcomes. 2003;1:59.

16. Flanagan JC. Measurement of quality of life: current state of the art. Arch Phys Med Rehabil. 1982:63(2):56-9.

17. Flanagan JC. Research approach to improving Our quality of life. Am Psychol. 1978;33(2):138-47.

18. Burckhardt CS, Anderson KL. The quality of life scale (QOLS): reliability, validity, and utilization. Health Qual Life Outcomes. 2003:1(1):60.

19. Heitmann K, Solheimsnes A, Havnen GC, Nordeng H, Holst L. Treatment of nausea and vomiting during pregnancy - a cross-sectional study among 712 Norwegian women. Eur J Clin Pharmacol. 2016;72(5):593-604.

20. Ebrahimi N, Maltepe C, Bournissen FG, Koren G. Nausea and vomiting of pregnancy: using the 24-hour pregnancy-unique quantification of emesis (PUQE-24) scale. J Obstet Gynaecol Can. 2009;31(9):803-7

21. Koren G, Piwko C, Ahn E, Boskovic R, Maltepe C, Einarson A, et al. Validation studies of the pregnancy unique-quantification of emesis (PUQE) scores. J Obstet Gynaecol. 2005;25(3):241-4.

22. Birkeland E, Stokke G, Tangvik RJ, Torkildsen EA, Boateng J, Wollen AL, et al. Norwegian PUQE (Pregnancy-Unique Quantification of Emesis and Nausea) Identifies Patients with Hyperemesis Gravidarum and Poor Nutritional Intake: 
A Prospective Cohort Validation Study. PloS one. 2016;10(4):e0119962. doi: 10.1371/journal.pone.0119962. eCollection 2015.

23. Vikanes A, Trovik J, Tellum T, Lomsdal S, Stensløkken A, Nesheim B-I. Clinical guideline "Hyperemesis" [Internet] Nordic Societies of Obstetrics and Gynecology. [cited on 19 October 2016]. Available from: http://www.nfog. org/quidelines.shtml (Hyperemesis)

24. Burckhardt CS, Woods SL, Schultz AA, Ziebarth DM. Quality of life of adults with chronic illness: a psychometric study. Res Nurs Health. 1989;12(6):347-54.

25. Offenbacher M, Sauer S, Kohls N, Waltz M, Schoeps P. Quality of life in patients with fibromyalgia: validation and psychometric properties of the German quality of life scale (QOLS-G). Rheumatol Int. 2012;32(10):3243-52.

26. Latorre-Roman PA, Martinez-Amat A, Martinez-Lopez E, Moral A, Santos MA, Hita-Contreras F. Validation and psychometric properties of the spanish version of the quality of life scale (QOLS) in patients with fibromyalgia. Rheumatol Int. 2014:34(4):543-9.

27. Wahl A, Burckhardt C, Wiklund I, Hanestad BR. The Norwegian version of the quality of life scale (QOLS-N). a validation and reliability study in patients suffering from psoriasis. Scand J Caring Sci. 1998;12(4):215-22.

28. Poursharif B, Korst LM, Macgibbon KW, Fejzo MS, Romero R, Goodwin TM. Elective pregnancy termination in a large cohort of women with hyperemesis gravidarum. Contraception. 2007;76(6):451-5.

29. Mazzotta P, Stewart DE, Koren G, Magee LA. Factors associated with elective termination of pregnancy among Canadian and american women with nausea and vomiting of pregnancy. J Psychosom Obstet Gynaecol. 2001; 22(1):7-12.

30. Mazzotta P, Stewart D, Atanackovic G, Koren G, Magee LA. Psychosocial morbidity among women with nausea and vomiting of pregnancy: prevalence and association with anti-emetic therapy. J Psychosom Obstet Gynaecol. 2000;21(3):129-36.

31. Norwegian media barometer - Table: 04519: Percentage internet users and minutes used for internet an average day, by sex and education [Internet]. Statistics Norway, 2015 [cited 08 July 2015]. Available from: https://www. ssb.no/statistikkbanken/selecttable/hovedtabellHjem.asp?KortNavnWeb= medie\& CMSSubjectArea=kultur-og-fritid\&PLanguage $=1 \&$ checked=true.

32. Eysenbach G. Improving the quality of Web surveys: the checklist for reporting results of internet E-surveys (CHERRIES). J Med Internet Res. 2004;6(3):e34.

33. van Gelder MM, Bretveld RW, Roeleveld N. Web-based questionnaires: the future in epidemiology? Am J Epidemiol. 2010;172(11):1292-8.

34. Ekman A, Dickman PW, Klint A, Weiderpass E, Litton JE. Feasibility of using web-based questionnaires in large population-based epidemiological studies. Eur J Epidemiol. 2006;21(2):103-11.

35. Whitehead L. Methodological issues in internet-mediated research: a randomized comparison of internet versus mailed questionnaires. J Med Internet Res. 2011;13(4):e109.

36. Ritter P, Lorig K, Laurent $\mathrm{D}$, Matthews $\mathrm{K}$. Internet versus mailed questionnaires: a randomized comparison. J Med Internet Res. 2004;6(3):e29.

37. Touvier M, Mejean C, Kesse-Guyot E, Pollet C, Malon A, Castetbon K, et al. Comparison between web-based and paper versions of a self-administered anthropometric questionnaire. Eur J Epidemiol. 2010;25(5):287-96.

38. Koren G, Maltepe C, Navioz Y, Wolpin J. Recall bias of the symptoms of nausea and vomiting of pregnancy. Am J Obstet Gynecol. 2004;190(2):485-8.

\section{Submit your next manuscript to BioMed Central and we will help you at every step:}

- We accept pre-submission inquiries

- Our selector tool helps you to find the most relevant journal

- We provide round the clock customer support

- Convenient online submission

- Thorough peer review

- Inclusion in PubMed and all major indexing services

- Maximum visibility for your research

Submit your manuscript at www.biomedcentral.com/submit
Biomed Central 